\title{
Finite-Time Output Feedback Control for a Rigid Hydraulic Manipulator System
}

\author{
Yong-Sheng Hao, ${ }^{1}$ Zhi-Gang Su $\mathbb{D}^{1},{ }^{1}$ and Xiangyu Wang ${ }^{2}{ }^{2}$ \\ ${ }^{1}$ School of Energy and Environment, Southeast University, Nanjing 210096, Jiangsu, China \\ ${ }^{2}$ School of Automation, Southeast University \& Key Laboratory of Measurement and Control of Complex Systems of Engineering, \\ Ministry of Education, Nanjing 210096, Jiangsu, China
}

Correspondence should be addressed to Xiangyu Wang; w.x.y@seu.edu.cn

Received 12 February 2018; Accepted 25 June 2018; Published 10 July 2018

Academic Editor: Xinkai Chen

Copyright (c) 2018 Yong-Sheng Hao et al. This is an open access article distributed under the Creative Commons Attribution License, which permits unrestricted use, distribution, and reproduction in any medium, provided the original work is properly cited.

\begin{abstract}
The position tracking control problem of a hydraulic manipulator system is investigated. By utilizing homogeneity theory, a finitetime output feedback controller is designed. Firstly, a finite-time state feedback controller is developed based on homogeneity theory. Secondly, a nonlinear state observer is designed to estimate the manipulator's velocity. A rigorous analysis process is presented to demonstrate the observer's finite-time stability. Finally, the corresponding output feedback tracking controller is derived, which stabilizes the tracking error system in finite time. Simulations demonstrate the effectiveness of the designed finitetime output feedback controller.
\end{abstract}

\section{Introduction}

In the past years, robotic system related control problem has been investigated more and more widely for robots application value $[1,2]$. In addition to rapid responses and high power-to-weight ratios [3-10], a great many robots are driven by hydraulic actuators. To improve the performance for industrial hydraulic machines, it is essential to enhance the control performance of manipulators actuated by hydraulic actuators [3, 4]. However, hydraulic manipulators control problem is more challenging than their electrical counterparts, due to the nonlinear dynamics and the nonlinear mechanical linkage dynamics. On one hand, mechanical linkage dynamics are composed of strong coupling effects among various joints and significant nonlinearities in the hydraulic actuators [4]. On the other hand, with complex properties of servo valves, frictions, compressibility of hydraulic fluid and volume changes $[5,6,11]$, and hydraulic actuators exhibit highly nonlinear characteristics. To realize more accurate control, the hydraulic actuators dynamics must be considered in the hydraulic manipulators control design $[4,12]$.

For the hydraulic manipulators position tracking control problem, researchers have proposed a great deal of meaningful results in recent years [3, 4, 12-16]. In [13], by using singular perturbation technique, a nonlinear control method was developed to solve the trajectory tracking control problem and the stabilization problem for 6-axis hydraulically actuated robots. Decentralized adaptive controllers were proposed for the hydraulic manipulators [14, 15]. For the Stewart-type hydraulic manipulator [16], a pressure feedback controller was presented, which allow very high proportional position error gains. However, these results have not paid much attention to stability analysis. In [3], based on Lyapunov stability theory, an adaptive robust control algorithm was proposed. With sliding mode control method, a robust control algorithm was presented in [4] to realize accurate position tracking for hydraulic manipulators. By combining pole placement technique, backstepping control, and sliding mode control together, a composite controller was designed in [12] to regulate both flexural vibrations and flexible arm motion.

In the above-mentioned literatures, the proposed methods just realize asymptotical stability for position control problems of hydraulic systems, which indicates that such systems are asymptotically stable with infinite settling time. Thus it is necessary to design more efficient controllers to offer faster convergence rates. To this end, finite-time control is a good choice. To realize finite-time control, nonsmooth 
control is a feasible choice. Besides faster convergence rates, nonsmooth control systems usually also possess some other superiorities, such as better disturbance rejection abilities and robustness [17]. Because of such nice features, nonsmooth control has been widely investigated from the perspectives of state feedback control [18], output feedback control [19-21], individual systems $[22,23]$, and multiagent systems [24-26].

Note that, in the above references, almost all the control designs are based on full-state information. However, in practice, in the case without velocity sensors, the manipulator velocity can not be measured directly. It is impractical to obtain the velocity information by differentiating the measured position, because derivation operation usually results in very noisy velocity data. To this end, an effective way is estimating the manipulator angular velocity via velocity observers.

In this paper, the position tracking control problem of the rigid hydraulic manipulator system is studied. Firstly, a finite-time state feedback controller is developed based on homogeneity theory. Secondly, in the case without angular velocity sensors, by utilizing homogeneous theory, a finitetime convergent observer is developed to obtain the angular velocity information for feedback. A rigorous stability analysis process is presented to demonstrate finite-time stability of the designed state observer. Thirdly, with the designed finitetime state feedback controller and the estimated angular velocity, a finite-time output feedback controller is given.

The remainder of this paper is arranged as follows. In Section 2, some preliminary knowledge is given. In Section 3, the model of the rigid hydraulic manipulator system is presented. The main results are presented in Section 4. Simulations on the proposed finite-time tracking controller are performed in Section 5. Finally, conclusions are drawn in Section 6.

\section{Preliminaries}

Denote $\operatorname{sig}^{\alpha}(x)=\operatorname{sign}(x)|x|^{\alpha}$, where $\alpha \geq 0, x \in R$. $\operatorname{sign}(\cdot)$ is the sign function. For a vector $x=\left[x_{1}, \ldots, x_{n}\right]^{\mathrm{T}} \in R^{n}$, the notation $\operatorname{sig}^{\alpha}(x)$ represents the vector $\left[\operatorname{sig}^{\alpha}\left(x_{1}\right), \ldots, \operatorname{sig}^{\alpha}\left(x_{n}\right)\right]^{\mathrm{T}}$, where $\alpha \geq 0$. The notation $x^{\beta}$ represents the vector $\left[x_{1}^{\beta}, \ldots, x_{n}^{\beta}\right]^{\mathrm{T}}$, where $\beta \in R \cdot \operatorname{diag}\left(x_{1}, \ldots, x_{n}\right)$ represents a diagonal matrix with the diagonal elements $x_{1}, \ldots, x_{n}$.

Consider the following nonlinear autonomous system:

$$
\dot{x}=f(x), \quad x \subseteq \mathbb{R}^{n}, f(0)=0,
$$

where $f: D \longrightarrow \mathbb{R}^{n}$ satisfies the locally Lipschitz continuous condition. Under this condition, the definition of finite-time stability can be described as follows.

Definition 1 (finite-time stability, [17]). The equilibrium $x=0$ of system (1) is finite-time convergent if there are an open neighbourhood $U$ of the origin and a function $T_{x}: U \backslash$ $\{0\} \longrightarrow(0, \infty)$, such that every solution trajectory $x\left(t, x_{0}\right)$ of system (1) starting from the initial point $x_{0} \in U \backslash\{0\}$ is welldefined and unique in forward time for $t \in\left[0, T_{x}\left(x_{0}\right)\right)$, and $\lim _{t \rightarrow T_{x}\left(x_{0}\right)} x\left(t, x_{0}\right)=0$. Here $T_{x}\left(x_{0}\right)$ is called the convergence time (with respect to the initial state $x_{0}$ ). The equilibrium of system (1) is finite-time stable if it is Lyapunov stable and finite-time convergent. If $U=D=\mathbb{R}^{n}$, the origin is a globally finite-time stable equilibrium.

Lemma 2 (see [27]). Consider the following system:

$$
\begin{aligned}
& \dot{x}_{1}=x_{2}, \ldots, \dot{x}_{n-1}=x_{n}, \\
& \dot{x}_{n}=u, \\
& y=x_{1} .
\end{aligned}
$$

There exists $\epsilon \in(0,1)$ such that, for every $\alpha \in(1-\epsilon, 1)$, the origin is a globally finite-time-stable equilibrium for system (2) under the feedback control law

$$
u=-k_{1} \operatorname{sig}^{\alpha_{1}}\left(x_{1}\right)-\cdots-k_{n} \operatorname{sig}^{\alpha_{n}}\left(x_{n}\right)
$$

where $k_{1}, \ldots, k_{n}>0$ are constants such that the polynomial $s^{n}+k_{n} s^{n-1}+\cdots+k_{2} s+k_{1}$ is Hurwitz and $\alpha_{1}, \ldots, \alpha_{n}$ satisfy $\alpha_{i-1}=\alpha_{i} \alpha_{i+1} /\left(2 \alpha_{i+1}-\alpha_{i}\right), i=2, \ldots, n$, with $\alpha_{n+1}=1$ and $\alpha_{n}=\alpha$.

Lemma 3 (see [19]). For system (2), there exists proper constants $a_{i}>0(i=1, \ldots, n)$, so that the observer shown below is finite-time convergent.

$$
\begin{gathered}
\dot{\hat{x}}_{1}=\widehat{x}_{2}+a_{1} \operatorname{sig}^{\alpha_{1}}\left(x_{1}-\widehat{x}_{1}\right), \\
\vdots \\
\dot{\hat{x}}_{n-1}=\widehat{x}_{n}+a_{n-1} \operatorname{sig}^{\alpha_{n-1}}\left(x_{1}-\widehat{x}_{1}\right), \\
\dot{\hat{x}}_{n}=u+a_{n} \operatorname{sig}^{\alpha_{n}}\left(x_{1}-\widehat{x}_{1}\right),
\end{gathered}
$$

where $\alpha_{i}=1+i \alpha, i=1, \ldots, n, \alpha \in(-1 / n, 0)$.

Lemma 4 (see [20]). Consider the following system:

$$
\dot{x}=f(x)+\widehat{f}(x), \quad f(0)=0, x \in \mathbb{R}^{n},
$$

where $f(x)$ is a continuously homogeneous function of degree $k<0$ with respect to $\left[r_{1}, \ldots, r_{n}\right]^{T}$ and $\widehat{f}(x)$ satisfies $\widehat{f}(0)=0$. If system $\dot{x}=f(x)$ is asymptotically stable, then system (5) is locally finite-time stable, when $\lim _{\varepsilon \rightarrow 0}\left(\widehat{f}_{i}\left(\varepsilon^{r_{1}} x_{1}\right.\right.$, $\left.\left.\ldots, \varepsilon^{r_{n}} x_{n}\right) / \varepsilon^{k+r_{i}}\right)=0, i=1, \ldots, n, \forall x \neq 0$.

\section{System Models and Problem Formulation}

In this section, the hydraulic actuator and the model of the n-link rigid manipulator are presented firstly. Then the integrated model of them is constructed.

3.1. Dynamic of the Hydraulic Actuator. The schematic of the rigid manipulator driven by single-rod hydraulic servo system is depicted in Figure 1. $P_{1}$ and $P_{2}$ represent the forward and return pressures of the cylinder, respectively. $Q_{1}$ is the supply flow rate to the forward chamber and $Q_{2}$ is the return flow rate to the return chamber. $A_{1}$ is the piston area facing the extending chamber and $A_{2}$ is the piston area facing the 


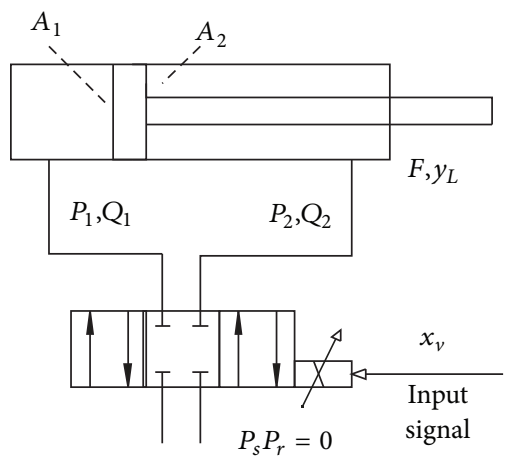

FIgURe 1: Hydraulic servo system.

retract chamber. $P_{s}$ is the supply pump pressure and $P_{r}$ is the return pressure.

From [28], the dynamics of the cylinder pressures $P_{1}$ and $P_{2}$ can be written as

$$
\begin{aligned}
& \dot{P}_{1}=\frac{\beta_{e}}{V_{1}}\left(Q_{1}-A_{1} \dot{y}_{L}-C_{t m}\left(P_{1}-P_{2}\right)\right), \\
& \dot{P}_{2}=\frac{\beta_{e}}{V_{2}}\left(A_{2} \dot{y}_{L}+C_{t m}\left(P_{1}-P_{2}\right)-Q_{2}\right),
\end{aligned}
$$

where $Q_{1}=k q_{1} x_{s} \phi_{1}\left(P_{1}, \operatorname{sign}\left(x_{s}\right)\right), Q_{2}=k q_{2} x_{s} \phi_{2}\left(P_{2}\right.$, $\left.\operatorname{sign}\left(x_{s}\right)\right), \phi_{1}\left(P_{1}, \operatorname{sign}\left(x_{s}\right)\right)$, and $\phi_{2}\left(P_{2}, \operatorname{sign}\left(x_{s}\right)\right)$ are defined as (7a) and (7b), $\beta_{e}$ is the effective bulk modulus of the hydraulic fluid, $V_{1}$ and $V_{2}$ are the extend chamber volume and the retract chamber volume, respectively, $y_{L}$ represents the piston displacement, and $C_{t m}$ is the coefficient of the cylinder internal leakage. It is noted that $V_{1}=V_{10}+A_{1} y_{L}$ and $V_{2}=V_{20}-A_{2} y_{L}$, where $V_{10}$ and $V_{20}$ are the two chamber volumes when $y_{L}=0$. It is assumed that $\phi_{1}\left(P_{1}, \operatorname{sign}\left(x_{s}\right)\right)>0$ and $\phi_{2}\left(P_{2}, \operatorname{sign}\left(x_{s}\right)\right)>0$ are given as follows.

$$
\begin{aligned}
& \phi_{1}\left(P_{1}, \operatorname{sign}\left(x_{s}\right)\right)= \begin{cases}\sqrt{P_{s}-P_{1}}, & \text { if } x_{s} \geq 0 \\
\sqrt{P_{1}-P_{r}}, & \text { if } x_{s}<0,\end{cases} \\
& \phi_{2}\left(P_{2}, \operatorname{sign}\left(x_{s}\right)\right)= \begin{cases}\sqrt{P_{2}-P_{r}}, & \text { if } x_{s} \geq 0 \\
\sqrt{P_{s}-P_{2}}, & \text { if } x_{s}<0 .\end{cases}
\end{aligned}
$$

The dynamic of the servo valve is

$$
\tau_{s} \dot{x}_{s}=-x_{s}+k_{s} u,
$$

where $x_{s}$ is the servo-valve displacement, $\tau_{s}$ is the time constant, $u$ is the input signal, and $k_{s}$ is the servo-valve gain. By neglecting the time constant of the servo valve, the servovalve dynamics can be simplified as $x_{s}=k_{s} u$. Hence, the spool displacement $x_{s}$ can be seen as the control input.

Note that piston displacement vector $\bar{y}_{L}=\left[y_{L_{1}}, \ldots, y_{L_{n}}\right]^{\mathrm{T}}$ is the function of joint angular position vector $q$. By letting $\bar{y}_{L}=f(q)$, it yields that $\dot{\bar{y}}_{L}=J(q) \dot{q}$, where $J(q)$ is a $n \times n$ matrix. Then the virtual work of the rigid hydraulic manipulator is $W=F^{\mathrm{T}} \delta \bar{y}_{L}=F^{\mathrm{T}} J(q) \delta q$, where $\delta \bar{y}_{L}$ is the actuators piston displacement vector and $\delta q$ is the virtual variation vector on $q$. The work of the generalized force is

$$
W=\tau^{\mathrm{T}} \delta q
$$

The net force is expressed as $F=P_{1} A_{1}-P_{2} A_{2}$. It follows from (9) that

$$
\tau=J^{\mathrm{T}}(q) F
$$

where $J(q)$ is Jacobian Matrix.

3.2. Dynamics of the Rigid Manipulator. By utilizing Lagrangian method, the dynamics of a n-link rigid manipulator are described as follows:

$$
M(q) \ddot{q}+C(q, \dot{q}) \dot{q}+G(q)=\tau,
$$

where $M(q)$ denotes the robot manipulator inertia matrix, $C(q, \dot{q}) \dot{q}$ represents the coriolis and centrifugal torques, $G(q)$ is the vector of gravitational torques, $q, \dot{q}, \ddot{q} \in R^{n}$ are the vectors of joint angular position, velocity, and acceleration, respectively, and $\tau \in R^{n}$ is the joint torques vector.

With the manipulator subsystem dynamic and the hydraulic subsystem model, the complete dynamic of a n-link rigid hydraulic manipulator will be constructed.

3.3. Dynamic of the Rigid Hydraulic Manipulator. Before proceeding, the following assumption on the desired position is presented.

Assumption 5. The desired position $q_{i d}(t)(i=1, \ldots, n)$ is third-order differentiable.

Assume that all the hydraulic actuators have the same structure. Let $q_{d}(t)=\left[q_{1 d}(t), \ldots, q_{n d}(t)\right]^{\mathrm{T}}$ and $\dot{q}_{d}(t)=$ $\left[\dot{q}_{1 d}(t), \ldots, \dot{q}_{n d}(t)\right]^{\mathrm{T}}$ signify the desired position vector and velocity vector of the joint angular. The tracking errors are defined as $e_{1}=\left[e_{11}, \ldots, e_{1 n}\right]^{\mathrm{T}}=q-q_{d}, e_{2}=\left[e_{21}, \ldots, e_{2 n}\right]^{\mathrm{T}}=$ $\dot{q}-\dot{q}_{d}$.

The complete model of the hydraulic manipulator system is written as

$$
\begin{aligned}
& \dot{e}_{1}=e_{2} \\
& \dot{e}_{2}=f_{2}(e)+g_{2}(e)\left(A_{1} e_{3}-A_{2} e_{4}\right) \\
& \dot{e}_{3}=f_{3}(e)+g_{3}(e, u) u \\
& \dot{e}_{4}=f_{4}(e)+g_{4}(e, u) u \\
& y=e_{1}+q_{d}
\end{aligned}
$$

where $e=\left[e_{1}^{\mathrm{T}}, e_{2}^{\mathrm{T}}, e_{3}^{\mathrm{T}}, e_{4}^{\mathrm{T}}\right]^{\mathrm{T}}$ is the system state vector, $f_{2}(e)=$ $-M^{-1}\left(e_{1}+q_{d}\right)\left(C\left(e_{1}+q_{d}, e_{2}+\dot{q}_{d}\right)\left(e_{2}+\dot{q}_{d}\right)+G\left(e_{1}+\right.\right.$ $\left.\left.q_{d}\right)\right)-\ddot{q}_{d}(t), g_{2}(e)=M^{-1}\left(e_{1}+q_{d}\right) J^{\mathrm{T}}\left(e_{1}+q_{d}\right), f_{3}(e)=$ $-\beta_{e} \operatorname{diag}\left(1 / V_{11}, \ldots, 1 / V_{1 n}\right)\left(A_{1} J\left(e_{1}+q_{d}\right)\left(e_{2}+\dot{q}_{d}\right)+\right.$ $\left.C_{t m}\left(e_{3}-e_{4}\right)\right), g_{3}(e, u)=\beta_{e} k q_{1} \times \operatorname{diag}\left(\left(1 / V_{11}\right) \phi_{1}\left(e_{31}\right.\right.$, $\left.\left.\operatorname{sign}\left(u_{1}\right)\right), \ldots,\left(1 / V_{1 n}\right) \phi_{1}\left(e_{3 n}, \operatorname{sign}\left(u_{n}\right)\right)\right), f_{4}(e)=\beta_{e} \operatorname{diag}(1 /$ $\left.V_{21}, \ldots, 1 / V_{2 n}\right)\left(A_{2} J\left(e_{1}+q_{d}\right)\left(e_{2}+\dot{q}_{d}\right)+C_{t m}\left(e_{3}-e_{4}\right)\right), g_{4}(e, u)=$ 
$-\beta_{e} k q_{2} \times \operatorname{diag}\left(\left(1 / V_{21}\right) \phi_{2}\left(e_{41}, \operatorname{sign}\left(u_{1}\right)\right), \ldots,\left(1 / V_{2 n}\right) \phi_{2}\left(e_{4 n}\right.\right.$, $\left.\left.\operatorname{sign}\left(u_{n}\right)\right)\right)$.

System (12) can be rewritten as

$$
\begin{aligned}
\dot{e}_{1} & =e_{2}, \\
\dot{e}_{2} & =\xi, \\
\dot{\xi} & =\varphi_{1}(e)+\varphi_{2}(e, u) u,
\end{aligned}
$$

where $\xi(e)=\left(\xi_{1}(e), \ldots, \xi_{n}(e)\right)^{\mathrm{T}}=f_{2}(e)+g_{2}\left(e_{1}\right)\left(A_{1} e_{3}-A_{2} e_{4}\right)$, $\varphi_{1}(e)=\dot{f}_{2}(e)+\dot{g}_{2}(e)\left(A_{1} x_{3}-A_{2} e_{4}\right)+g_{2}(e)\left(A_{1} f_{3}(e)-A_{2} f_{4}(e)\right)$, $\varphi_{2}(e, u)=g_{2}(e)\left(A_{1} g_{3}(e, u)-A_{2} g_{4}(e, u)\right)$.

In the following section, the finite-time position tracking controller will be designed for the rigid hydraulic manipulator system.

\section{Output Feedback Control Design}

Main results are given in this section. Firstly, a state feedback controller will be developed for tracking error system (13). Then a finite-time state observer and the corresponding output feedback controller are given.

\subsection{State Feedback Control Design}

Theorem 6. For tracking error system (13), if the controller is designed as

$$
\begin{aligned}
\varphi_{2}(e, u) u= & -\varphi_{1}(e)-k_{1} \operatorname{sig}^{\alpha_{1}}\left(e_{1}\right)-k_{2} \operatorname{sig}^{\alpha_{2}}\left(e_{2}\right) \\
& -k_{3} \operatorname{sig}^{\alpha_{3}}(\xi),
\end{aligned}
$$

where $k_{1}, k_{2}, k_{3}, \alpha_{1}, \alpha_{2}, \alpha_{3}$ satisfy the constraint conditions in Lemma 2, the closed-loop system (13) and (14) is finite-time stable; i.e., the manipulator position will track the desired position accurately in finite time.

Proof. Closed-loop system (13) and (14) can be written as

$$
\begin{aligned}
& \dot{e}_{1}=e_{2}, \\
& \dot{e}_{2}=\xi \\
& \dot{\xi}=-k_{1} \operatorname{sig}^{\alpha_{1}}\left(e_{1}\right)-k_{2} \operatorname{sig}^{\alpha_{2}}\left(e_{2}\right)-k_{3} \operatorname{sig}^{\alpha_{3}}(\xi) .
\end{aligned}
$$

From Lemma 2, it is concluded that system (15) is finite-time stable. This completes the proof.

4.2. State Observer and Output Feedback Control Design. In the case without an angular velocity sensor, the angular velocity of the manipulator cannot be measured directly. To reconstruct the angular velocity information, a state observer will be designed.

Let $x_{1}=\left[x_{11}, \ldots, x_{1 n}\right]^{\mathrm{T}}=q, x_{2}=\left[x_{21}, \ldots, x_{2 n}\right]^{\mathrm{T}}=\dot{q}$. The rigid manipulator system is written as

$$
\begin{aligned}
& \dot{x}_{1}=x_{2}, \\
& \dot{x}_{2}=M^{-1}\left(x_{1}\right)\left(-C\left(x_{1}, x_{2}\right) x_{2}-G\left(x_{1}\right)+\tau\right) .
\end{aligned}
$$

Theorem 7. For system (16), the system state $x_{2}$ can be accurately estimated in finite time by the following observer:

$$
\begin{aligned}
\dot{\hat{x}}_{1}= & \widehat{x}_{2}-l_{1} \operatorname{sig}^{\sigma_{1}}\left(\widehat{x}_{1}-x_{1}\right), \\
\dot{\hat{x}}_{2}= & M^{-1}\left(x_{1}\right)\left(-C\left(x_{1}, \widehat{x}_{2}\right) \widehat{x}_{2}-G\left(x_{1}\right)+\tau\right) \\
& -l_{2} \operatorname{sig}^{\sigma_{2}}\left(\hat{x}_{1}-x_{1}\right),
\end{aligned}
$$

where $l_{1}>0, l_{2}>0, \sigma_{1}=\sigma, \sigma_{2}=2 \sigma-1, \sigma \in(1 / 2,1)$.

Proof. Let $w_{1}=\widehat{x}_{1}-x_{1}, w_{2}=\widehat{x}_{2}-x_{2}$. The observation error system is written as follows:

$$
\begin{aligned}
\dot{w}_{1} & =w_{2}-l_{1} \operatorname{sig}^{\sigma_{1}}\left(w_{1}\right), \\
\dot{w}_{2} & =M^{-1}\left(x_{1}\right) \\
& \cdot\left(C\left(x_{1}, x_{2}\right) x_{2}-C\left(x_{1}, w_{2}+x_{2}\right)\left(w_{2}+x_{2}\right)\right) \\
& -l_{2} \operatorname{sig}^{\sigma_{2}}\left(w_{1}\right) .
\end{aligned}
$$

Consider the following reduced system of (18):

$$
\begin{aligned}
& \dot{w}_{1}=w_{2}-l_{1} \operatorname{sig}^{\sigma_{1}}\left(w_{1}\right), \\
& \dot{w}_{2}=-l_{2} \operatorname{sig}^{\sigma_{2}}\left(w_{1}\right) .
\end{aligned}
$$

System (19) is homogeneous of degree $k=\alpha-1<$ 0 with respect to the dilation $r=\left[r_{1}, r_{2}\right]^{T}=[1, \alpha]^{T}$. From Lemma 3, system (19) is finite-time stable. Let $h\left(w_{1}\right.$, $\left.w_{2}\right)=M^{-1}\left(x_{1}\right)\left(C\left(x_{1}, x_{2}\right) x_{2}-C\left(x_{1}, w_{2}+x_{2}\right)\left(w_{2}+x_{2}\right)\right)$. It follows that $\lim _{\varepsilon \longrightarrow 0}\left(h\left(\varepsilon^{r_{1}} w_{1}, \varepsilon^{r_{2}} w_{2}\right) / \varepsilon^{k+r_{2}}\right)=\lim _{\varepsilon \rightarrow 0}(1 /$ $\left.\varepsilon^{k+r_{2}}\right)\left[M^{-1}\left(x_{1}\right)\left(C\left(x_{1}, x_{2}\right) x_{2}-C\left(x_{1}, \varepsilon^{r_{2}} w_{2}+x_{2}\right)\left(\varepsilon^{r_{2}} w_{2}+x_{2}\right)\right)\right]=$ $\lim _{\varepsilon \rightarrow 0}-M^{-1}\left(x_{1}\right) C\left(x_{1}, \varepsilon^{r_{2}} w_{2}+x_{2}\right) w_{2} \varepsilon^{-k}=0$. From Lemma 4, it is concluded that observation error system (18) is finitetime stable; i.e., the states of system (16) will be accurately estimated in finite time. This completes the proof.

Based on Theorems 6 and 7, for the position tracking control problem, the finite-time output feedback controller is designed as

$$
\begin{aligned}
\varphi_{2}(\widehat{e}, u) u= & -\varphi_{1}(\widehat{e})-k_{1} \operatorname{sig}^{\alpha_{1}}\left(\widehat{e}_{1}\right)-k_{2} \operatorname{sig}^{\alpha_{2}}\left(\widehat{e}_{2}\right) \\
& -k_{3} \operatorname{sig}^{\alpha_{3}}(\xi),
\end{aligned}
$$

where $\widehat{e}=\left[\widehat{e}_{1}, \widehat{e}_{2}\right]^{T}, \widehat{e}_{1}=x_{1}-q_{d}, \widehat{e}_{2}=\widehat{x}_{2}-\dot{q}_{d}$.

Remark 8. Since $\varphi_{2}(\widehat{e}, u)$ is a function of $u$, thus controller (20) is coupled. However, from the point view of practice, the coupled controller should be decoupled. Note that $\phi_{1}(\cdot)>$ $0, \phi_{2}(\cdot)>0, A_{1}>0, A_{2}>0, V_{1 i}>0, V_{2 i}>0$. Let $Z=\left[z_{1}, \ldots, z_{n}\right]^{T}=g_{2}^{-1}(\widehat{e})\left(-\varphi_{1}(\widehat{e})-k_{1} \operatorname{sig}^{\alpha_{1}}\left(\widehat{e}_{1}\right)-\right.$ $\left.k_{2} \operatorname{sig}^{\alpha_{2}}\left(\widehat{e}_{2}\right)-k_{3} \operatorname{sig}^{\alpha_{3}}(\xi)\right)$. Then, the coupled controller $(20)$ can be decoupled as

$$
\begin{array}{ll}
u_{i} & \begin{cases}\frac{Z_{i}}{A_{1} \beta_{e} k_{q_{1}} \sqrt{P_{s}-e_{3 i}} / V_{1 i}+A_{2} \beta_{e} k_{q_{2}} \sqrt{e_{4 i}-P_{r}} / V_{2 i}}, & Z_{i} \geq 0 \\
\frac{Z_{i}}{A_{1} \beta_{e} k_{q_{1}} \sqrt{e_{3 i}-P_{r}} / V_{1 i}+A_{2} \beta_{e} k_{q_{2}} \sqrt{P_{s}-e_{4 i}} / V_{2 i}}, & Z_{i}<0\end{cases}
\end{array}
$$




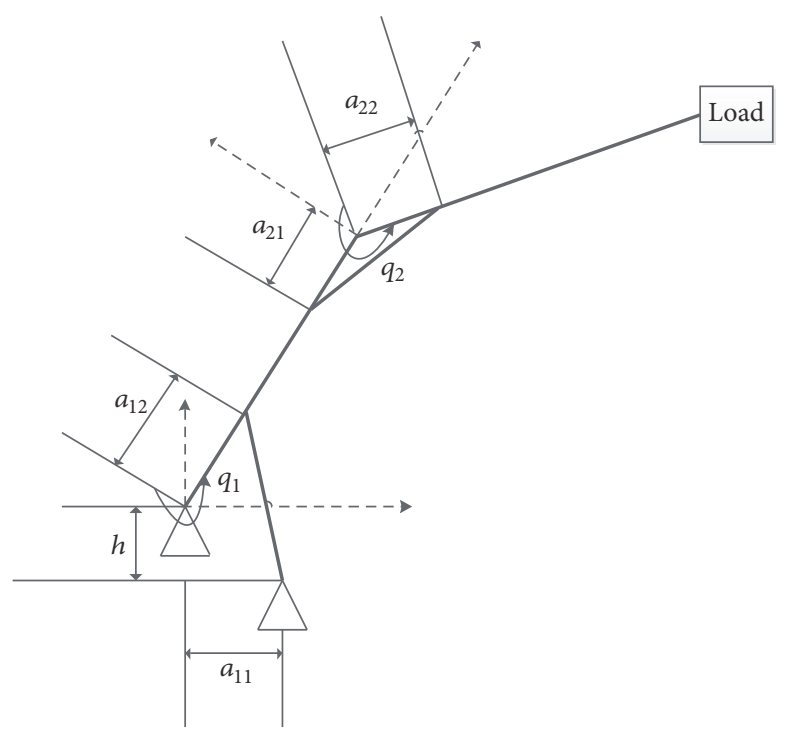

FIgURE 2: Two-link hydraulic manipulator model.

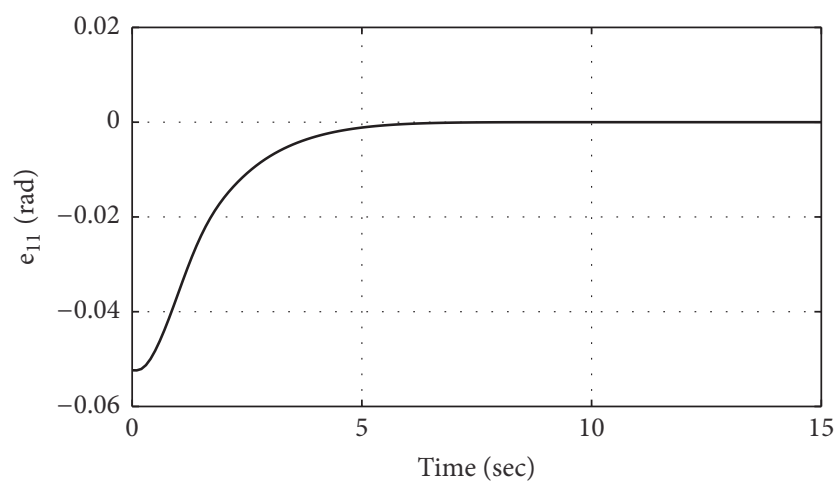

(a)

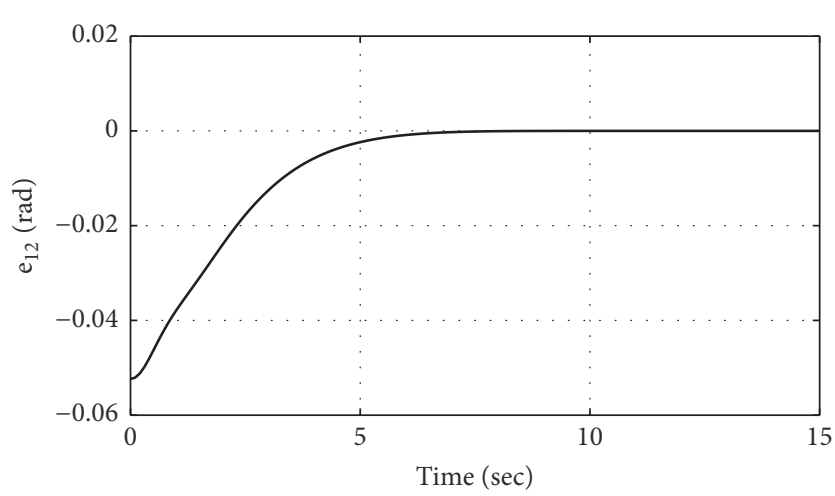

(c)

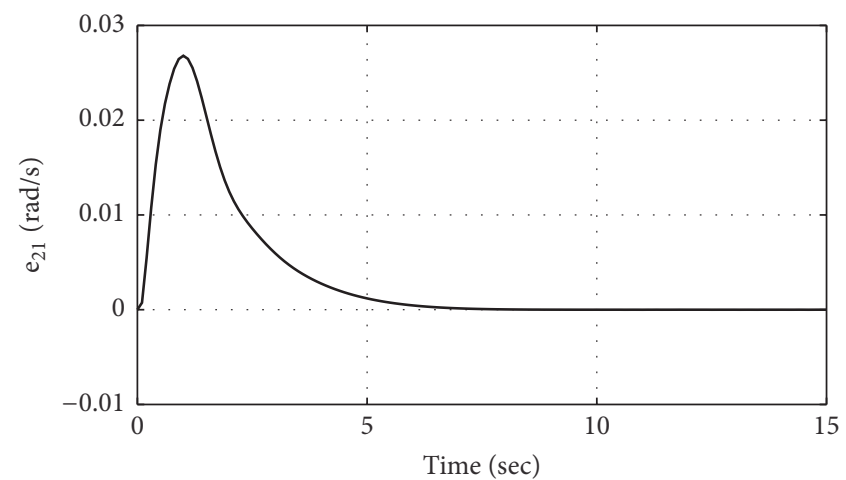

(b)

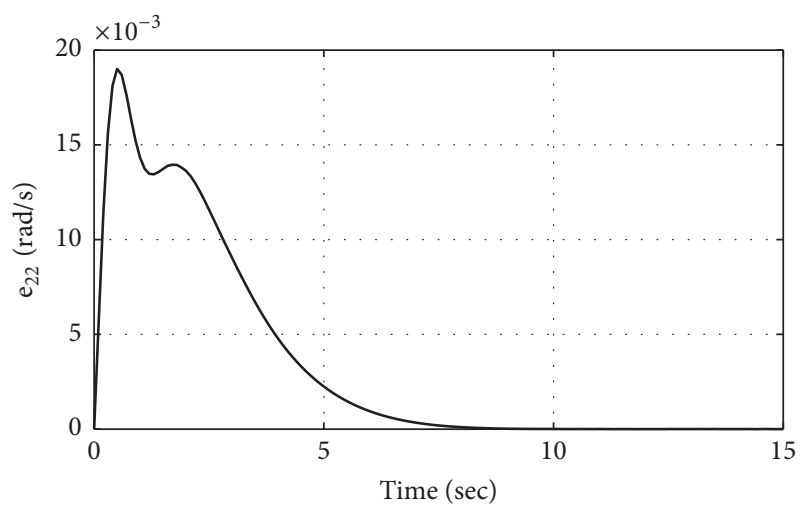

(d)

FIgure 3: Tracking errors under controller (20). (a) Position tracking error of the first link. (b) Velocity tracking error of the first link. (c) Position tracking error of the second link. (d) Velocity tracking error of the second link.

\section{Numerical Simulations}

In this section, simulations are performed on a two-link rigid hydraulic manipulator to illustrate the effectiveness of the proposed control method. The model of a two-link rigid manipulator is presented in Figure 2. The inertia matrix, coriolis, and centrifugal torques and gravitational torques are described as $M(q)=\left[M_{11}, M_{12} ; M_{12}, M_{22}\right]$, where $M_{11}=$ $m_{1} l_{c_{1}}^{2}+I_{1}+m_{2}\left(l_{1}^{2}+l_{c_{2}}^{2}+2 l_{1} l_{c_{2}} \cos \left(q_{2}\right)\right)+I_{2}+m_{p}\left(l_{1}^{2}+\right.$ $\left.l_{2}^{2}+2 l_{1} l_{2} \cos \left(q_{2}\right)\right), M_{12}=m_{2}\left(l_{1} l_{c_{2}} \cos \left(q_{2}\right)+l_{c_{2}}^{2}\right)+I_{2}+$ $m_{p}\left(l_{2}^{2}+l_{1} l_{2} \cos \left(q_{2}\right)\right), M_{22}=m_{2} l_{c_{2}}^{2}+I_{2}+m_{p} l_{2}^{2} \cdot C(q)=$ 


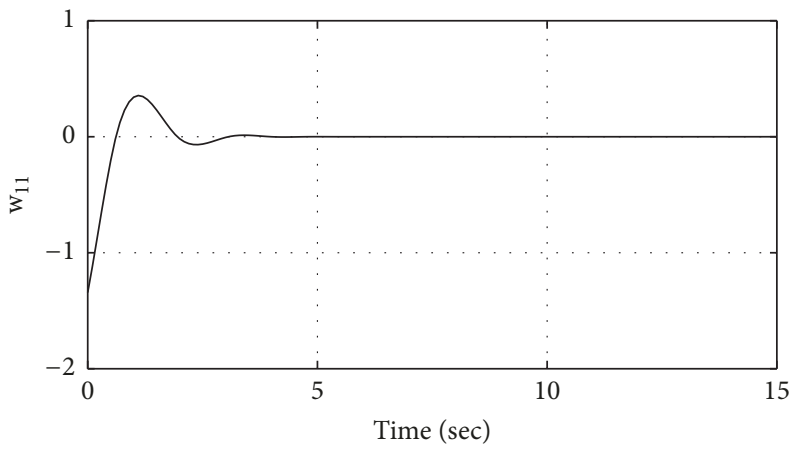

(a)

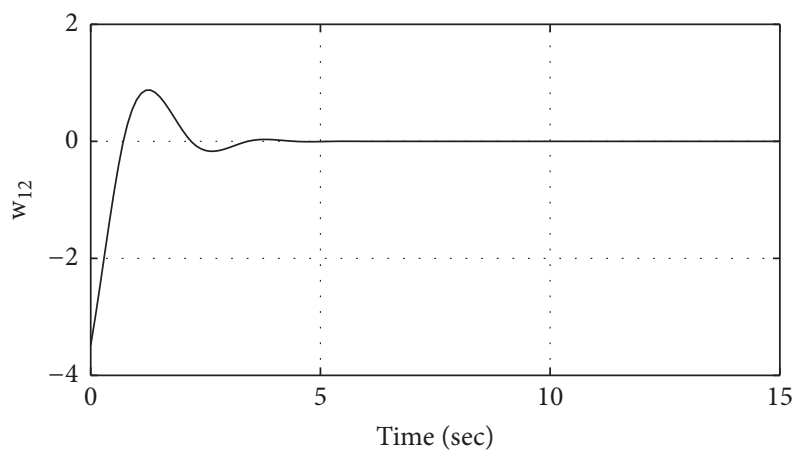

(c)

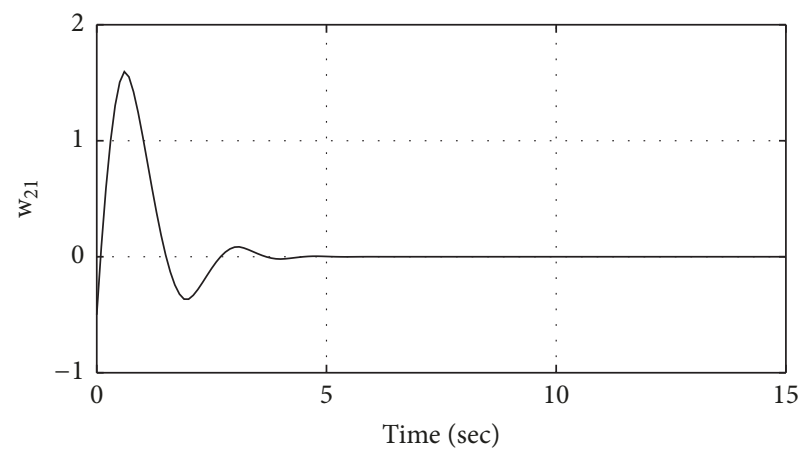

(b)

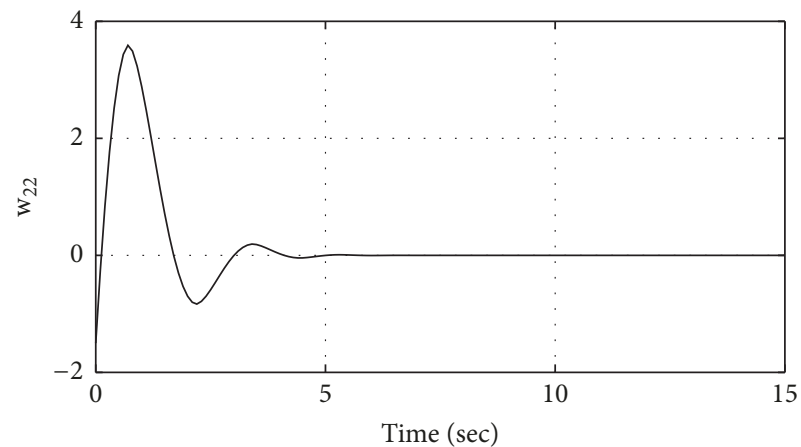

(d)

FIGURE 4: Observation errors. (a) Observation error of $x_{11}$. (b) Observation error of $x_{21}$. (c) Observation error of $x_{12}$. (d) Observation error of $x_{22}$.

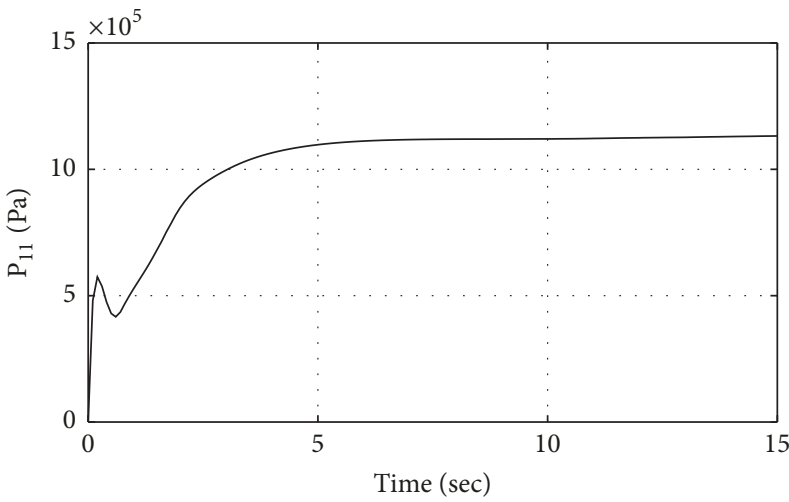

(a)

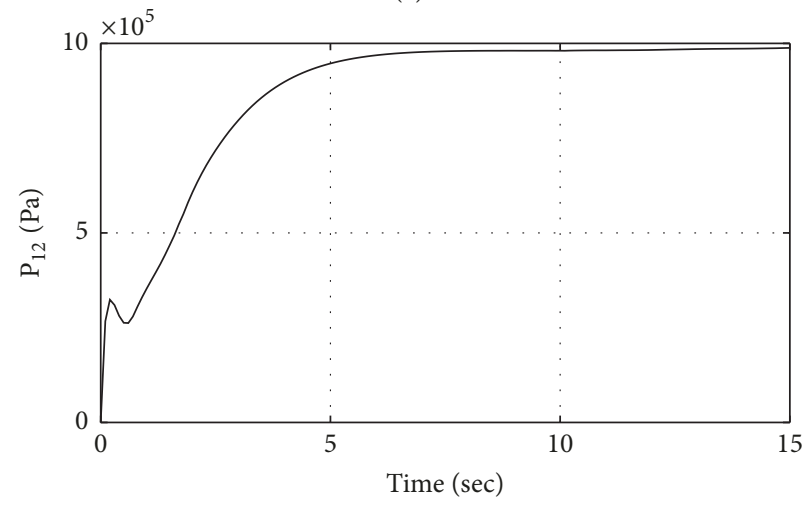

(c)

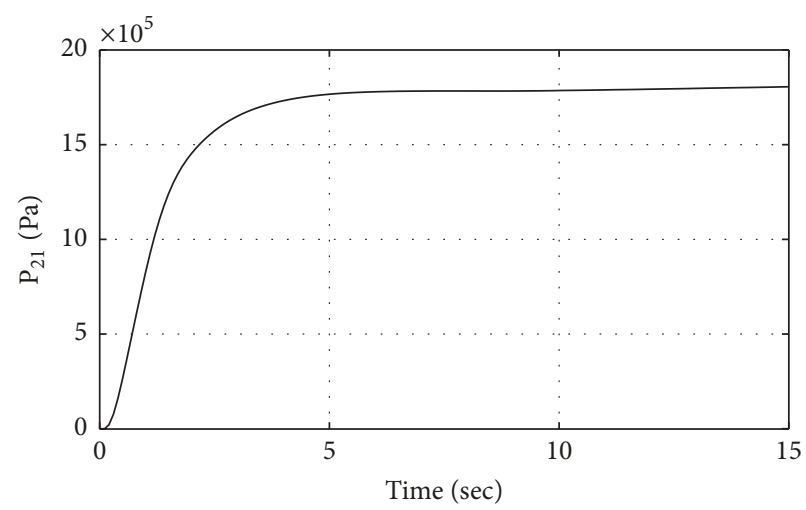

(b)

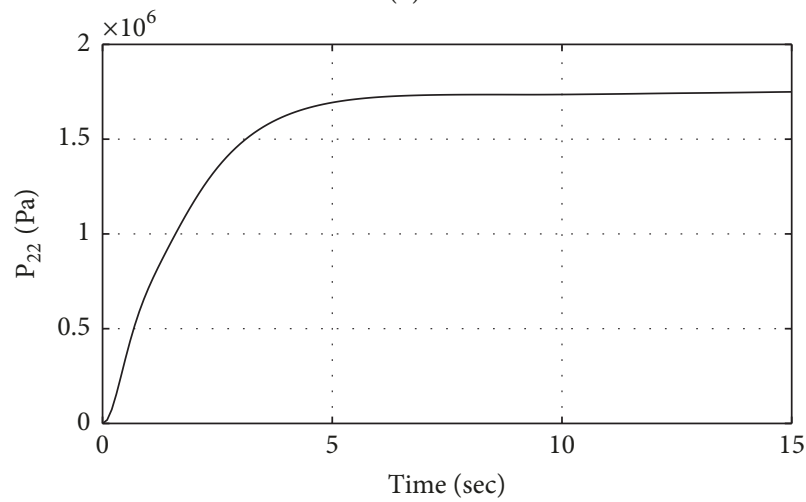

(d)

Figure 5: Pressures in the cylinders. (a) Forward pressure in the first actuator. (b) Forward pressure in the second actuator. (c) Return pressure in the first actuator. (d) Return pressure in the second actuator. 


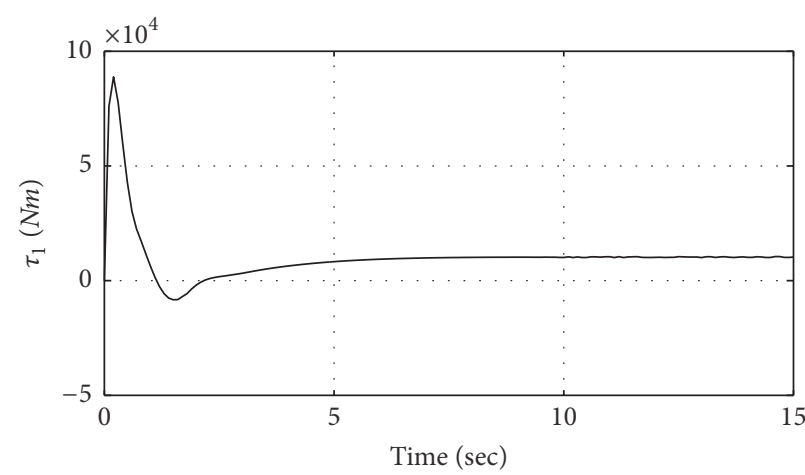

(a)

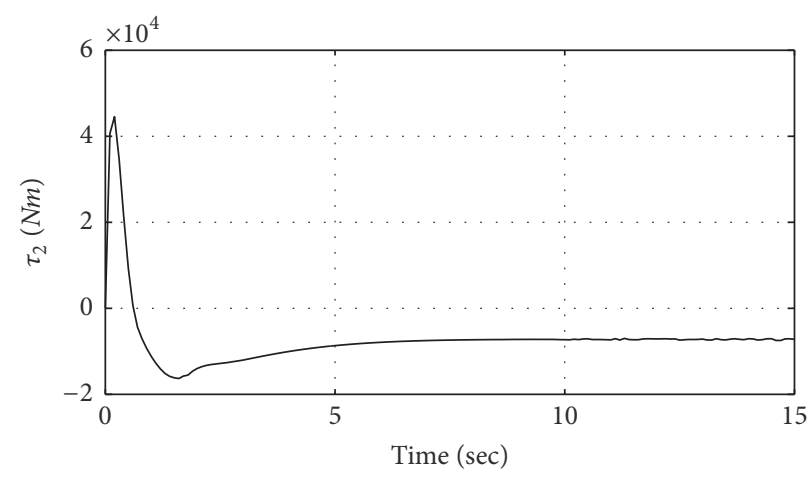

(b)

FIgURE 6: The joint torques. (a) Joint torque of the first link. (b) Joint torque of the second link.

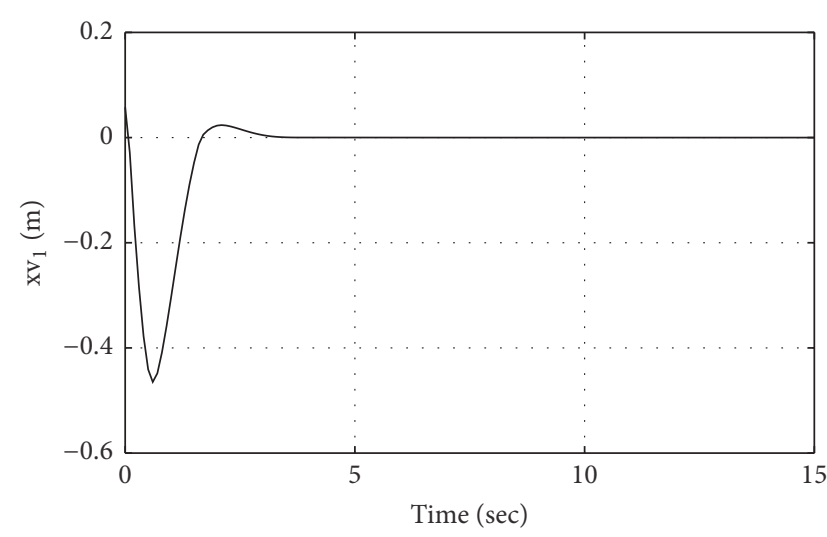

(a)

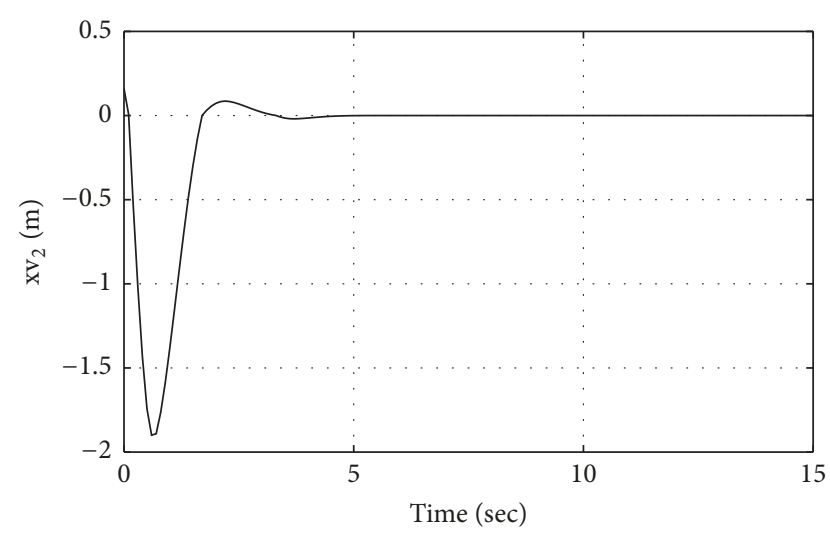

(b)

Figure 7: Servo-valve displacements. (a) Servo-valve displacement of the first link. (b) Servo-valve displacement of the second link.

$\left[C_{11}, C_{12} ; C_{12}, C_{22}\right]$, where $C_{11}=-h_{1} \dot{q}_{2}, C_{12}=-h_{1} \dot{q}_{2}-h_{1} \dot{q}_{1}$, $C_{21}=h_{2} \dot{q}_{1}-h_{3} \dot{q}_{2}, C_{22}=0$, where $h_{1}=\left(m_{2} l_{1} l_{c_{2}}+\right.$ $\left.m_{p} l_{1} l_{2}\right) \sin \left(q_{2}\right), h_{2}=m_{2} l_{1} l_{c_{2}} \sin \left(q_{2}\right), h_{3}=m_{p} l_{1} l_{2} \sin \left(q_{2}\right)$. $G(q)=\left[G_{1}(q), G_{2}(q)\right]^{T}$, where $G_{1}(q)=\left(m_{1} l_{c_{1}}+m_{2} l_{1}+\right.$ $\left.m_{p} l_{1}\right) g \cos \left(q_{1}\right)+\left(m_{2} l_{c_{2}}+m_{p} l_{2}\right) g \cos \left(q_{1}+q_{2}\right), G_{2}(q)=\left(m_{2} l_{c_{2}}+\right.$ $\left.m_{p} l_{2}\right) g \cos \left(q_{1}+q_{2}\right)$. The servo-valve displacements are $y_{L_{1}}=$ $\left(a_{11}^{2}+a_{12}^{2}-2 a_{11} a_{12} \cos \left(q_{1}\right)+h^{2}+2 h a_{12} \sin \left(q_{1}\right)\right)^{1 / 2}, y_{L_{2}}=$ $\left[a_{21}^{2}+a_{22}^{2}+2 a_{21} a_{22} \cos \left(q_{2}\right)\right]^{1 / 2}$, where $h$ is the horizontal distance between the bottom of the lower base and the top of the higher base, which is shown at the bottom of Figure 2. The Jacobian Matrix is $J=\left[J_{1}, 0 ; 0, J_{2}\right]$, where $J_{1}=$ $\left(a_{11} a_{12} \sin \left(q_{1}\right)+h a_{12} \cos \left(q_{1}\right)\right) / y_{L_{1}}, J_{2}=-a_{21} a_{22} \sin \left(q_{2}\right) / y_{L_{2}}$.

Model parameters of the hydraulic actuators and the manipulator, borrowed from [29], are given as follows. Parameters of the manipulator are $l_{1}=3.2 \mathrm{~m}, l_{c_{1}}=1.6 \mathrm{~m}$, $l_{2}=2.6 \mathrm{~m}, l_{c_{2}}=1.3 \mathrm{~m}, I_{1}=516.3 \mathrm{kgm}^{2}, I_{2}=323.2 \mathrm{kgm}^{2}, m_{1}=$ $300 \mathrm{~kg}, m_{2}=220 \mathrm{~kg}, m_{p}=200 \mathrm{~kg}, a_{11}=0.4 \mathrm{~m}, a_{21}=0.4 \mathrm{~m}$, $a_{12}=0.4 \mathrm{~m}, a_{22}=0.4 \mathrm{~m}, h=0.3 \mathrm{~m}, g=9.8 \mathrm{~m} / \mathrm{s}^{2}$. Parameters of the hydraulic manipulator are $C_{t m}=3.0 \times 10^{-12} \mathrm{~m}^{5} / \mathrm{Ns}$, $\beta_{e}=6.013 \times 10^{8} \mathrm{~Pa}, P_{s}=1.034 \times 10^{7} \mathrm{~Pa}, P_{r}=0 \mathrm{~Pa}, C_{d}=0.61$, $w=0.023 \mathrm{~m}, \rho=842 \mathrm{~kg} / \mathrm{m}^{3}, k q_{i}=4.835 \times 10^{-4} \mathrm{~m}^{5 / 2} / \sqrt{\mathrm{kg}}$, $A_{1}=2.463 \times 10^{-3} \mathrm{~m}^{2}, A_{2}=1.455 \times 10^{-3} \mathrm{~m}^{2}, V_{10}=$ $7.239 \times 10^{-4} \mathrm{~m}^{3}, V_{20}=5.021 \times 10^{-4} \mathrm{~m}^{3}$.
The parameters for observer (17) are chosen as $l_{1}=2, l_{2}=$ $5, \sigma_{1}=8 / 9, \sigma_{2}=7 / 9$. The parameters of controller (20) are chosen as $k_{1}=4, k_{2}=9, k_{3}=4.5, \alpha_{1}=4 / 7, \alpha_{2}=\frac{2}{3}, \alpha_{3}=4 / 5$.

Simulation results are presented in Figures 3-7. Figure 3 shows that the manipulator tracks the desired position and velocity accurately in finite time. Figure 4 presents the observation errors of observer (17). The observation errors converge to zero in finite time. The pressure in the cylinders is shown in Figure 5. Figure 6 presents the joint torques of the manipulators. Figure 7 gives the displacement of the servo valve.

\section{Conclusions}

This paper has studied the finite-time output feedback position tracking control problem for a rigid hydraulic manipulator system. Based on homogeneity theory, in the case without velocity sensors, the finite-time state observer is proposed to estimate the manipulator velocity. With the velocity estimates, the finite-time output feedback controller is developed by utilizing homogeneity theory. Numerical simulations have shown the effectiveness of the proposed output feedback controller. 


\section{Data Availability}

The data used to support the findings of this study are available from the corresponding author upon request.

\section{Conflicts of Interest}

The authors declare that they have no conflicts of interest.

\section{Acknowledgments}

This work was supported by the National Natural Science Foundation of China under Grants 51676034 and 61503078.

\section{References}

[1] Y. Xie, X. Wu, Z. Shi, Z. Wang, J. Sun, and T. Hao, "The path planning of space manipulator based on Gauss-Newton iteration method," Advances in Mechanical Engineering, vol. 9, no. 8, pp. 1-12, 2017.

[2] X. Wang, D. Zhang, and C. Zhao, "The inverse kinematics of a 7R 6-degree-of-freedom robot with non-spherical wrist," Advances in Mechanical Engineering, vol. 9, no. 8, pp. 1-11, 2017.

[3] J. Yao, W. Deng, and Z. Jiao, "Adaptive control of hydraulic actuators with LuGre model-based friction compensation," IEEE Transactions on Industrial Electronics, vol. 62, no. 10, pp. 6469-6477, 2015.

[4] N. Z. Azlan and J. H. S. Osman, "Modeling and proportional integral sliding mode control of hydraulic manipulators," in Proceedings of the 2006 4th Student Conference on Research and Development "Towards Enhancing Research Excellence in the Region", SCOReD 2006, pp. 137-143, Selangor, Malaysia, June 2006.

[5] C. Guan and S. Pan, "Nonlinear adaptive robust control of single-rod electro-hydraulic actuator with unknown nonlinear parameters," IEEE Transactions on Control Systems Technology, vol. 16, no. 3, pp. 434-445, 2008.

[6] S. Liu and B. Yao, "Coordinate control of energy saving programmable valves," IEEE Transactions on Control Systems Technology, vol. 16, no. 1, pp. 34-45, 2008.

[7] Q. Guo, T. Yu, and D. Jiang, "High-gain observer-based output feedback control of single-rod electro-hydraulic actuator," IET Control Theory \& Applications, vol. 9, no. 16, pp. 2395-2404, 2015.

[8] S. A. Ali, A. Christen, S. Begg, and N. Langlois, "ContinuousDiscrete Time-Observer Design for State and Disturbance Estimation of Electro-Hydraulic Actuator Systems," IEEE Transactions on Industrial Electronics, vol. 63, no. 7, pp. 4314-4324, 2016.

[9] S. Sakaino, T. Furuya, and T. Tsuji, "Bilateral Control between Electric and Hydraulic Actuators Using Linearization of Hydraulic Actuators," IEEE Transactions on Industrial Electronics, vol. 64, no. 6, pp. 4631-4641, 2017.

[10] H. Zhou, L. Lao, Y. Chen, and H. Yang, "Discrete-time sliding mode control with an input filter for an electro-hydraulic actuator," IET Control Theory \& Applications, vol. 11, no. 9, pp. 1333-1340, 2017.

[11] W. Kim, D. Won, and C. C. Chung, "High gain observer based nonlinear position control for electro-hydraulic servo systems," in Proceedings of the American Control Conference (ACC'10), pp. 1440-1446, Baltimore, Md, USA, July 2010.
[12] G. Li and A. Khajepour, "Robust control of a hydraulically driven flexible arm using backstepping technique," Journal of Sound and Vibration, vol. 280, no. 3-5, pp. 759-775, 2005.

[13] B. d'Andrea-Novel, M. A. Garnero, and A. Abichou, "Nonlinear control of a hydraulic robot using singular perturbations," in Proceedings of the 1994 IEEE International Conference on Systems, Man and Cybernetics. Part 1 (of 3), pp. 1932-1937, San Antonio, TX, USA, October 1994.

[14] K. A. Edge and F. G. de Almeida, "Decentralized adaptive control of a directly driven hydraulic manipulator Part I: theory," Proceedings of the Institution of Mechanical Engineers, vol. 209, no. 13, pp. 191-196, 1995.

[15] K. A. Edge and F. G. de Almeida, "Decentralized adaptive control of a directly driven hydraulic manipulator Part II: experiments," Proceedings of the Institution of Mechanical Engineers, vol. 209, no. 13, pp. 197-202, 1995.

[16] D. Li and S. E. Salcudean, "Modeling, simulation and control of a hydraulic Stewart platform," in Proceedings of the IEEE International Conference on Robotics and Automation (ICRA 1997), pp. 3360-3366, Albuquerque, NM, USA, 1997.

[17] S. P. Bhat and D. S. Bernstein, "Finite-time stability of continuous autonomous systems," SIAM Journal on Control and Optimization, vol. 38, no. 3, pp. 751-766, 2000.

[18] C. Qian and W. Lin, "A continuous feedback approach to global strong stabilization of nonlinear systems," IEEE Transactions on Automatic Control, vol. 46, no. 7, pp. 1061-1079, 2001.

[19] H. Du, C. Qian, S. Yang, and S. Li, "Recursive design of finitetime convergent observers for a class of time-varying nonlinear systems," Automatica, vol. 49, no. 2, pp. 601-609, 2013.

[20] Y. Hong, J. Huang, and Y. Xu, "On an output feedback finitetime stabilization problem," IEEE Transactions on Automatic Control, vol. 46, no. 2, pp. 305-309, 2001.

[21] C. Qian and J. Li, "Global finite-time stabilization by output feedback for planar systems without observable linearization," IEEE Transactions on Automatic Control, vol. 50, no. 6, pp. 885890, 2005.

[22] X. Wang, X. Sun, S. Li, and H. Ye, "Output feedback domination approach for finite-time force control of an electrohydraulic actuator," IET Control Theory \& Applications, vol. 6, no. 7, pp. 921-934, 2012.

[23] F. Wang, Q. Zou, C. Hua, and Q. Zong, "Finite-time attitude tracking control design for reusable launch vehicle in reentry phase based on disturbance observer," Advances in Mechanical Engineering, vol. 9, no. 12, pp. 1-13, 2017.

[24] S. H. Li and X. W. Wang, "Finite-time consensus and collision avoidance control algorithms for multiple AUVs," Automatica, vol. 49, no. 11, pp. 3359-3367, 2013.

[25] X. Wang, S. Li, X. Yu, and J. Yang, "Distributed active antidisturbance consensus for leader-follower higher-order multiagent systems with mismatched disturbances," Institute of Electrical and Electronics Engineers Transactions on Automatic Control, vol. 62, no. 11, pp. 5795-5801, 2017.

[26] G. Li, X. Wang, and S. Li, "Finite-Time Output Consensus of Higher-Order Multiagent Systems With Mismatched Disturbances and Unknown State Elements," IEEE Transactions on Systems, Man, and Cybernetics: Systems, pp. 1-11, 2017.

[27] S. P. Bhat and D. S. Bernstein, "Geometric homogeneity with applications to finite-time stability," Mathematics of Control, Signals, and Systems, vol. 17, no. 2, pp. 101-127, 2005.

[28] M. A. Avila, A. G. Loukianov, and E. N. Sanchez, "Electrohydraulic actuator trajectory tracking," in Proceedings of the 
American Control Conference (AAC '04), vol. 3, pp. 2603-2608, IEEE, Boston, Mass, USA, July 2004.

[29] X. Wang, X. Sun, S. Li, and H. Ye, "Finite-time position tracking control of rigid hydraulic manipulators based on highorder terminal sliding mode," Proceedings of the Institution of Mechanical Engineers, Part I: Journal of Systems and Control Engineering, vol. 226, no. 3, pp. 394-414, 2012. 


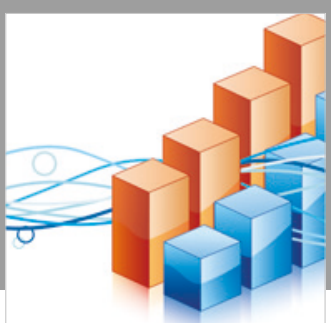

Advances in

Operations Research

\section{-n-m}
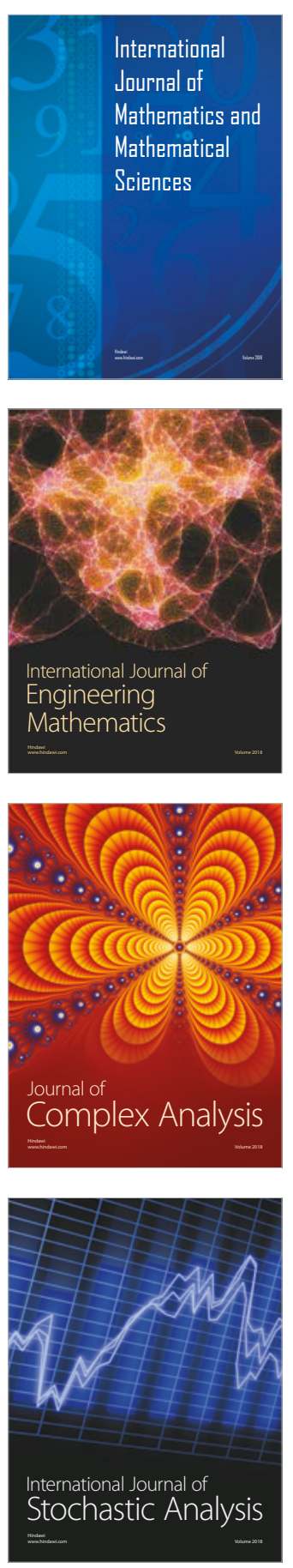
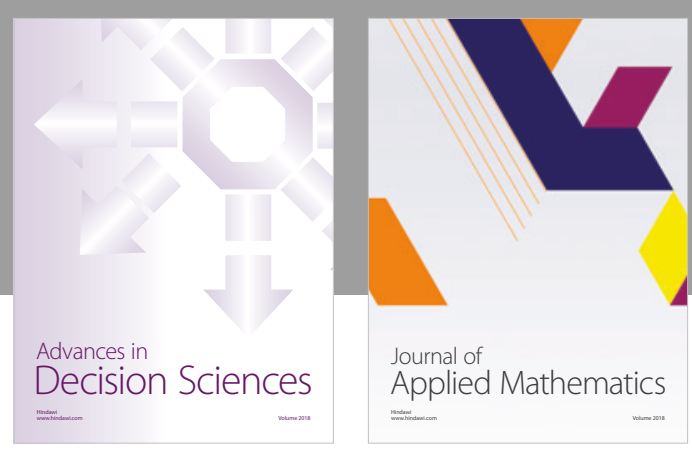

Journal of

Applied Mathematics
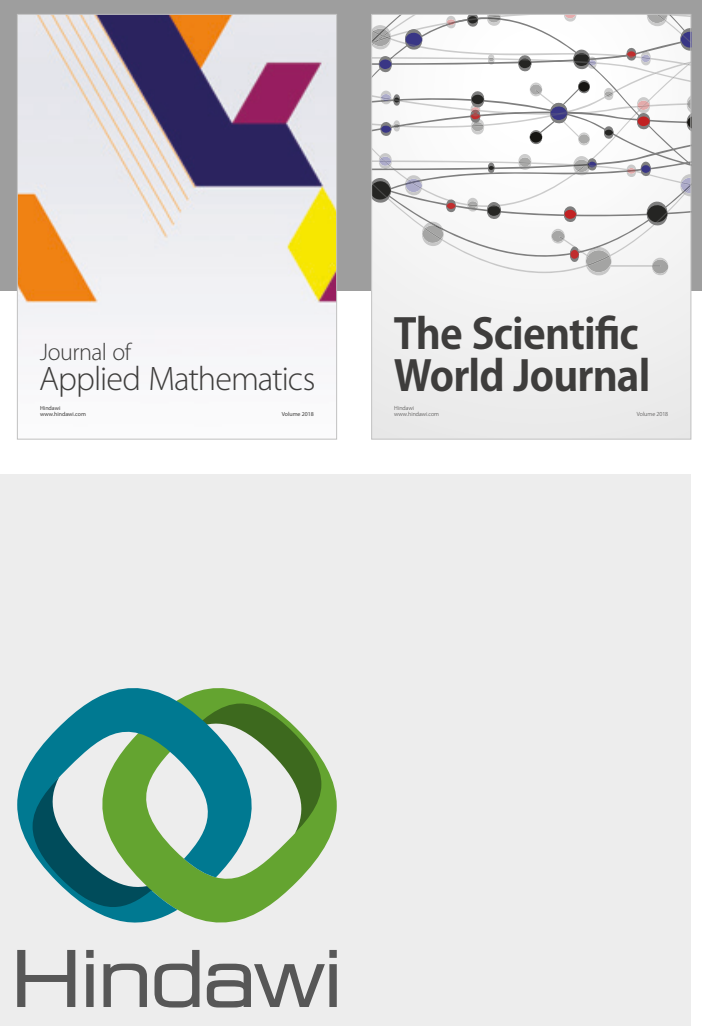

Submit your manuscripts at

www.hindawi.com

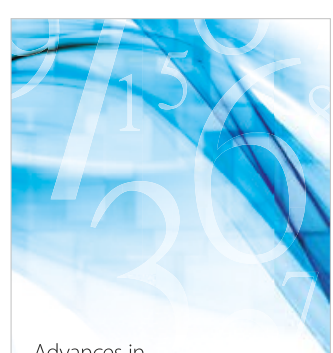

Advances in
Numerical Analysis
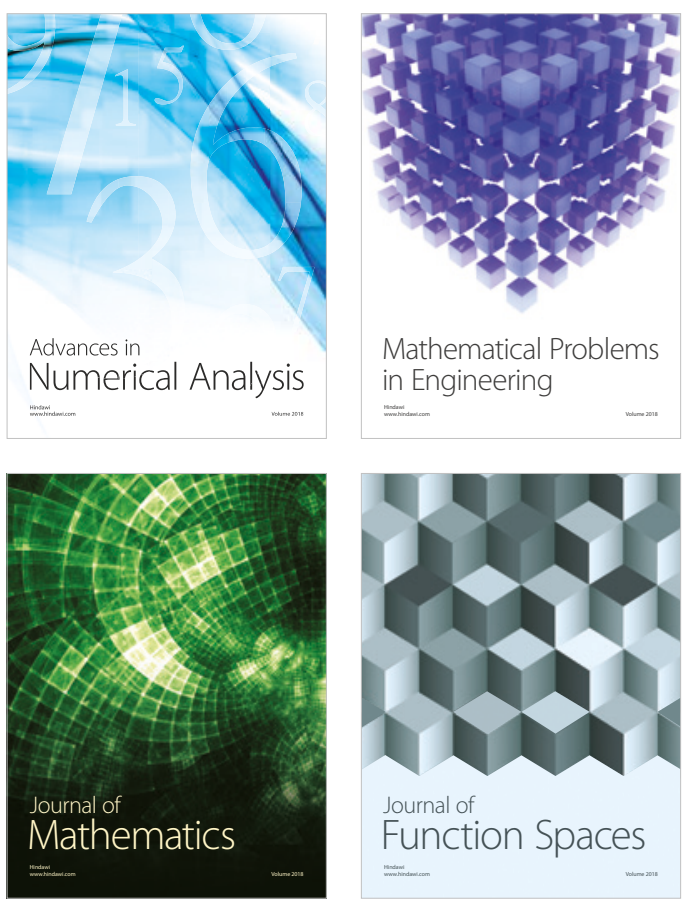

Mathematical Problems in Engineering

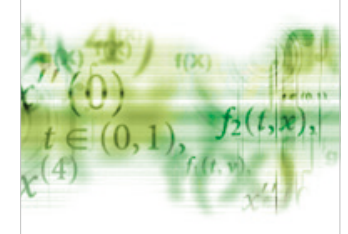

International Journal of

Differential Equations

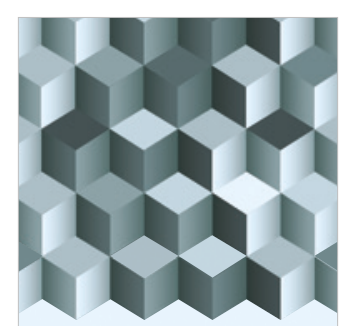

Journal of

Function Spaces

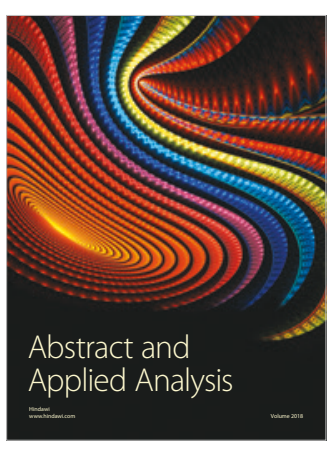

The Scientific

World Journal

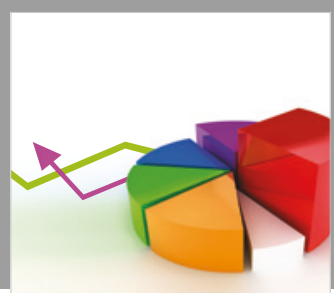

Journal of

Probability and Statistics
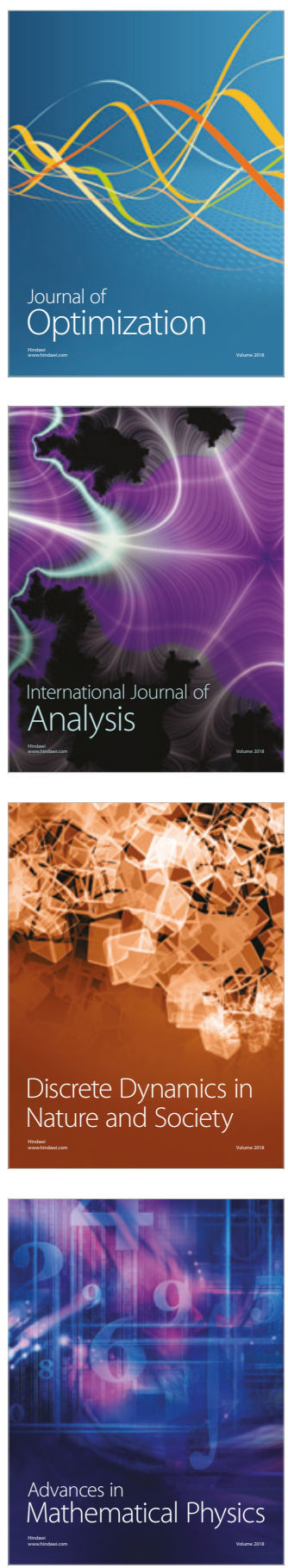